\title{
Reactivation of NCAM1 Defines a Subpopulation of Human Adult Kidney Epithelial Cells with Clonogenic and Stem/Progenitor Properties
}

\author{
Ella Buzhor,${ }^{* \dagger}$ Dorit Omer, ${ }^{* \dagger}$ Orit Harari-Steinberg, ${ }^{* \dagger}$ Zohar Dotan, ${ }^{\ddagger}$ Einav Vax, ${ }^{* \dagger}$ Sara Pri-Chen, ${ }^{* \S}$ Sally Metsuyanim, ${ }^{*}$ \\ Oren Pleniceanu, ${ }^{* \dagger}$ Ronald S. Goldstein, ${ }^{\top}$ and Benjamin Dekel ${ }^{* \dagger \|}$
}

From the Pediatric Stem Cell Research Institute* and the Division of Pediatric Nephrology, ${ }^{\|}$Safra Children's Hospital, the Sheba Center for Regenerative
Medicine, ${ }^{\dagger}$ the Department of Urology, ${ }^{\ddagger}$ and the Maurice and Gabriela Goldschleger Eye Research Institute, ${ }^{\S}$ Sheba Medical Center, Tel Hashomer, Sackler
Faculty of Medicine, Tel Aviv University, Ramat-Gan; and the Mina and Everard Goodman Faculty of Life Sciences, ${ }^{\circledR}$ Bar-Ilan University, Ramat-Gan, Israel

Accepted for publication

July 22, 2013

Address correspondence to Benjamin Dekel, M.D., Ph.D., Pediatric Stem Cell Research Institute, Edmond and Lili Safra Children's Hospital, Sheba Medical Center, Tel Hashomer, 52621, Israel. E-mail: benjamin.dekel@gmail.com or binyamin.dekel@sheba.health. gov.il.

Kidney disease is a major worldwide health burden. Given the limited number of treatments currently available, discovering novel ways to stimulate kidney repair is an important therapeutic goal. Many adult tissues (such as skin, the hematopoietic system, and the intestine) are considered to harbor cells that self-renew and differentiate to form clones of stem, progenitor, and mature cells of the organ, fitting within the criteria of tissue-specific multipotential stem cells. ${ }^{1-4}$ In contrast to these rapidly cycling organs, parenchymal cells of the kidney are considered to be mostly static under steadystate conditions and can be induced to divide only under very specific conditions, limiting the overall regenerative capacity of the nephron, the kidney's functional unit. ${ }^{5}$ All nephron epithelia arise from a self-renewing nephron progenitor population that resides in the metanephric mesenchyme of the developing kidney's nephrogenic zone, specifically in the condensed mesenchyme that interacts with the ureteric bud, the precursor for the collecting system and undergoes mesenchymal-epithelial transition (MET). With

\footnotetext{
Supported by Israel Science Foundation grant no. 1139/07; the Israel Ministry of Industry 'NOFAR' program; Wolfson Clore Mayer; Tel Aviv University Stem Cell Research Center; and the Sackler School of Medicine, Tel Aviv University (all to B.D.).

E.B. and D.O. contributed equally to this work.

This study was performed in partial fulfillment of the requirements for the Ph.D. degree (E.B.).
} 
the completion of mammalian nephrogenesis (gestational week 34 in humans, 2 postnatal weeks in mice), this undifferentiated nephron-forming progenitor population is entirely exhausted. Therefore, in contrast to fish, ${ }^{6}$ no progenitor population with nephrogenic potential similar to the metanephric mesenchyme or condensed mesenchyme physiologically exists in the mammalian adult kidney. ${ }^{7,8}$

Using microarrays, we have previously characterized the renal epithelial progenitor population of the developing human kidney. ${ }^{9}$ Our results showed expression of a set of genes, including transcription factors that specify nephron lineage and are considered nephron progenitor markers, ${ }^{10,11}$ a polycomb group, and Wnt pathway molecules concomitant with several surface antigens such as NCAM1. After validation by fluorescence-activated cell sorting (FACS) analysis, we demonstrated the usefulness of NCAM1 for immunoselection strategies and cell sorting of specific human developmental renal progenitor subsets. ${ }^{9,12,13}$ After cessation of nephrogenesis, the early nephron progenitor markers are down-regulated in both murine kidneys ${ }^{7}$ and human ${ }^{8}$ kidneys. Similarly, NCAM1, which is strongly expressed in the condensed mesenchyme, nephrogenic zone, and in Wilms' tumor progenitor blastema, is not expressed in mature kidney epithelia after nephron differentiation. ${ }^{12-15}$

Here, we show that isolates of human kidney epithelia grown under adherent conditions proliferate and activate NCAM1 in a specific cell subset showing early renal stem/ progenitor characteristics and function. The in vitro identification of distinct $\mathrm{NCAM}^{+}$clone-forming cells and the possible beneficial role of $\mathrm{NCAM}^{+}$cells in regenerating kidney epithelia in vivo suggest NCAM1 as a target for manipulation for an enhanced regenerative response.

\section{Materials and Methods}

\section{hKEpC Cultures}

Normal human adult kidney samples were retrieved from borders of renal cell carcinoma tumors from patients undergoing partial or total nephrectomy at Sheba Medical Center and Wolfson Hospital. This procedure was performed after approval by the local ethical committee and signed informed consent from the patient. The samples were minced in Hanks' balanced salt solution, soaked in collagenase for 2 hours, and then cultured in serum-containing medium (SCM), which consisted of Iscove's modified Dulbecco's medium supplemented with $10 \%$ fetal bovine serum, $1 \%$ L-glutamine, $1 \%$ penicillin-streptomycin, and the following growth factors: $50 \mathrm{ng} / \mathrm{mL}$ bFGF, $50 \mathrm{ng} / \mathrm{mL}$ EGF, and $5 \mathrm{ng} / \mathrm{mL}$ SCF (R\&D Systems, Minneapolis, MN). Serum-free medium (SFM) consisted of $500 \mathrm{~mL}$ Dulbecco's modified Eagle's medium/ F12 (DMEM/F12, 1:1; Life Technologies, Carlsbad, CA), $1 \%$ penicillin-streptomycin, $2 \mathrm{~mL}$ B27 supplement (Life Technologies), $4 \mu \mathrm{g} / \mathrm{mL}$ heparin, $1 \%$ nonessential amino acids (Life Technologies), 1\% sodium pyruvate (Life Technologies), $1 \%$ L-glutamine, $1 \mathrm{~mL}$ lipid mix (Sigma-Aldrich, St.
Louis, MO), $5 \mathrm{~mL} 100 \times \mathrm{N} 2$ supplement (Life Technologies), $5 \mathrm{~mL}$ growth factor mix [200 mL of growth factor mix containing $100 \mathrm{~mL}$ DMEM/F12, $4 \mathrm{~mL} \mathrm{30 \%} \mathrm{glucose,} 200 \mathrm{mg}$ transferrin, $50 \mathrm{mg}$ insulin in $20 \mathrm{~mL}$ of water, $19.3 \mathrm{mg}$ putrescine in $20 \mathrm{~mL}$ distilled water, $200 \mu \mathrm{L}$ sodium selenate ( $0.3 \mathrm{mmol} / \mathrm{L}$ stock), $20 \mu \mathrm{L}$ progesterone $(2 \mathrm{mmol} / \mathrm{L}$ stock $)$, $10 \mathrm{ng} / \mathrm{mL}$ FGF, and $20 \mathrm{ng} / \mathrm{mL}$ EGF. Sphere formation was tested by seeding the cells in polyHEMA (Sigma-Aldrich) precoated plates in SFM. Fetal kidney conditioned medium (FKCM) was obtained by combining SCM and supernatants from fetal kidney cultures (cultured in SCM) of passages 1 to 3 at a 1:1 ratio.

\section{Cell Preparation and Sorting}

Monolayer cells were detached from culture plates with $0.25 \%$ trypsin (Life Technologies). Viable cell number was determined using Trypan Blue staining (Life Technologies). In magnetic-activated cell sorting (MACS), CD56 (NCAM1) microbeads (Miltenyi Biotec, Auburn, CA) were used for single-marker cell separation. Positive and negative fractions were separated using Mini or Midi MACS columns (Miltenyi Biotec), according to the manufacturer's protocol. In FACS sorting, cells were sorted with anti-NCAM-phycoerythrin (PE) (eBioscience, San Diego, CA) using a FACSAria fluorescence-activated cell sorter and FACSDiva software version 4.0 (BD Biosciences, San Jose, CA), as described previously. ${ }^{14}$

\section{Gene Expression Analysis of the Separated Cell Fractions}

Quantitative real-time RT-PCR (RT-qPCR) reactions were performed as described previously. ${ }^{12,16}$ In brief, total RNA from cells was isolated using an RNeasy micro kit (Qiagen, Hilden, Germany; Valencia, CA), according to the manufacturer's instructions. cDNA was synthesized using a highcapacity cDNA reverse-transcription kit (Life Technologies) on total RNA. qPCR was performed using an ABI 7900HT sequence detection system (Life Technologies) in the presence of TaqMan gene expression master mix (Life Technologies), and PCR amplification was performed using gene-specific TaqMan gene expression assay premade kits. Each analysis reaction was performed in duplicate or triplicate. GAPDH and HPRT1 were used as endogenous control throughout all experiments. Analysis was performed using the $\Delta \Delta C T$ method, which determines fold change in gene expression relative to a comparator sample. PCR results were analyzed using SDS RQ Manager software version 1.2 (Life Technologies).

\section{Clonogenicity of hKEpCs}

Limiting dilution assay was performed on total human adult kidney or separated $\mathrm{NCAM}^{+}$versus $\mathrm{NCAM}^{-}$cell fractions. In brief, sorted cells were plated in 96-well plates 
(Greiner Bio-One, Frickenhausen, Germany) in $150 \mu \mathrm{L}$ of culture medium, at 1 or 5 cells per well. The number of colonized wells was recorded after 2 to 4 weeks. Confluent viable clones of total hKEpCs were isolated and propagated.

\section{Proliferation Assay}

$\mathrm{NCAM}^{+}$and $\mathrm{NCAM}^{-}$cell fractions were subjected to CellTiter 96 AQ nonradioactive cell proliferation (Promega, Madison, WI), based on the novel tetrazolium compound 3(4,5-dimethylthiazol-2-yl)-5-(3-carboxymethoxyphenyl)-2(4-sulfophenyl)-2H-tetrazolium (MTS), according to the manufacturer's protocol. Wavelength for optical density is $450 \mathrm{~nm}$.

\section{In Vitro Differentiation Assays}

Osteogenic differentiation of NCAM1 ${ }^{+}$cells was performed in NH OsteoDiff medium (Miltenyi Biotec), according to the manufacturer's protocol. NCAM $1^{+}$cells were seeded at a concentration of $7.5 \times 10^{3}$ cells per well $(1 \mathrm{~mL}$ medium per well) in 24-well plates and were incubated for 10 days. Osteoblast detection was performed by staining for alkaline phosphatase activity with an alkaline phosphatase kit (Sigma-Aldrich), according to the manufacturer's protocol.

Adipogenic differentiation of $\mathrm{NCAM}^{+}$cells was performed in $\mathrm{NH}$ AdipoDiff medium (Miltenyi Biotec), according to the manufacturer's protocol. $\mathrm{NCAM}^{+}$cells were seeded at a concentration of $12.5 \times 10^{3}$ cells per well ( $1 \mathrm{~mL}$ medium per well) in 24-well plates and were incubated for 21 days. Adipocyte detection was performed by staining with Oil Red O solution (Sigma-Aldrich).

DMEM was used as a control for differentiation assessment in both assays.

\section{Microarray Analysis}

Human adult renal $\mathrm{NCAM}^{+}$and $\mathrm{NCAM}^{-}$cell fractions obtained from one adult donor were evaluated using Affymetrix HU GENE1.0ORD oligonucleotide arrays (Affymetrix technical note: Data sheet: GeneChip HuGene 1.0 ST Array System for Human, Mouse and Rat. Santa Clara, CA). Total RNA from each sample was used to prepare biotinylated target DNA, according to the manufacturer's recommendations. Target cDNA generated from each sample was processed using an Affymetrix Gene Chip instrument system [Affymetrix technical note: User Manual: GeneChip Whole Transcript (WT) Sense Target Labeling Assay. Santa Clara, CA]. The quality and amount of starting RNA was confirmed using agarose gel or by use of an Agilent 2100 Bioanalyzer (Agilent Technologies, Santa Clara, CA).

When scanning was done, array images were assessed by eye to confirm scanner alignment and the absence of significant bubbles or scratches on the chip surface. The signals derived from the array were assessed using various quality assessment metrics. Details of quality control are provided in the Affymetrix data sheet cited above. Gene-level RMA sketch algorithm [Affymetrix Expression Console and Partek Genomics Suite version 6.2 (Partek, St. Louis, MO)] was used for generation of crude data. Significantly changed genes were filtered as changed by at least twofold $(P=0.05)$. Genes were filtered and analyzed using unsupervised and supervised hierarchical cluster analysis [Partek Genomics Suite and Spotfire DecisionSite for Functional Genomics version 9.1.2 (TIBCO Spotfire, Somerville, MA)] to get a first assessment of the data. Further processing included functional analysis and over-representation calculations based on Gene Ontology and using the publicly available Database for Annotation, Visualization and Integrated Discovery and associated tools (DAVID tools version 6.7; http://david.abcc.ncifcrf.gov). Over-representation calculations were performed using the DAVID Ease tool, according to the Affymetrix technical notes cited above. Ingenuity Pathway Analysis software (IPA version 7; Ingenuity Systems, Redwood City, CA) was used for network analysis. The microarray data were deposited with the Gene Expression Omnibus (http://www.ncbi.nlm.nih.gov/geo; accession no. GSE49100).

\section{Nephron Segment-Specific Staining of NCAM1 ${ }^{+}$and NCAM1 ${ }^{-}$Cell Fractions in Culture}

Tubular segments were identified using the segment-specific markers. Proximal tubules were identified with biotinylated Lotus tetragonolobus lectin (LTA) (1:200, Vector Laboratories) and aminopeptidase A (ENPEP) (1:75; SigmaAldrich); distal tubules and collecting ducts were identified with biotinylated Dolichos biflorus agglutinin (DBA) (1:200; Vector Laboratories); and epithelial cells were identified with cytokeratin (1:250; Dako). Before staining, cells were fixed in ice-cold 95\% ethanol-5\% acetic acid for 10 minutes, washed in PBS, and blocked with $0.1 \%$ bovine serum albumin in PBS for 1 hour. Detection was performed with streptavidin Alexa Fluor 488 (1:1000, Jackson ImmunoResearch Laboratories) and anti-rabbit Alexa Fluor 488 (1:1000; Life Technologies). Slides were counterstained with ProLong Gold antifade reagent with DAPI (Life Technologies). Photomicrographs were made on a Nikon TI-E inverted microscope.

\section{Immunotoxin (huN901-DM1) Assay in Vitro}

Lorvotuzumab mertansine (alias huN901-DM1 or IMGN901) is a humanized version of the anti-CD56 antibody N901, conjugated to the highly cytotoxic maytansine derivative DM1 via a hindered disulfide linker ${ }^{17}$ (ImmunoGen, Waltham, MA).

\section{Estimation of the Proliferation Rate of hKEpCs}

hKEpCs were cultured at concentrations of 500, 1000, 2000, and 4000 cells per well in 96-well plates. After 1, 3, 5, and 7 days in culture, cell proliferation was evaluated using the 
MTS cell proliferation assay (Promega). Cell plating concentration (cells per well) for the huN901-DM1 assays was based on a sufficient amount of cells at the beginning of the experiment so as not to reach confluence (and therefore massive cell death) by the end of the experiment.

\section{Determination of the $\mathrm{LD}_{50}$ of huN901-DM1 on hKEpCs}

To determine the $\mathrm{LD}_{50}$ of huN901-DM1 for hKEpCs, cells were seeded in 96-well plates at $10^{4}$ cells per well for 24 hours in growth medium, which was then replaced with medium containing the conjugate in a range of concentrations between $1.6 \mathrm{nmol} / \mathrm{L}$ and $1.675 \mu \mathrm{mol} / \mathrm{L}$, with medium alone serving as a control. After a 5-day incubation period, cell survival was assessed by the MTS proliferation assay and $\mathrm{LD}_{50}$ was determined.

\section{huN901-DM1 Assay}

hKEpCs were seeded at $2 \times 10^{4}$ cells per well in six-well plates in duplicate and were treated with anti-NCAM antibody (huN901), anti-NCAM antibody conjugated with immunotoxin (huN901-DM1; $0.1 \mu \mathrm{mol} / \mathrm{L}$ ), or control. On day 5 of treatment, cells from all groups were subjected to limiting dilution, sphere formation, FACS, and MTS assays.

\section{Grafting hKEpC NCAM1 ${ }^{+}$Cells on the Chick Embryo CAM}

Grafting of hKEpC NCAM1 ${ }^{+}$cells on the chick embryo CAM was performed as described previously. ${ }^{16,18}$ In brief, fertile chicken eggs were obtained from a commercial supplier and incubated at $37^{\circ} \mathrm{C}$. On day 9 or 10 of incubation, a window was opened in the shell, and the CAM was exposed. hKEp NCAM1 ${ }^{+}$cells separated by MACS were suspended in $50 \mu \mathrm{L}$ medium and Matrigel (BD Biosciences) ( $1: 1$ by volume) and pipetted into a plastic ring placed on the chorioallantoic membrane (CAM). The egg was then sealed with adhesive tape and returned to the incubator. After 1 week, the graft was removed, paraffin-embedded, and serially sectioned at $6 \mu \mathrm{m}$ for histological and immunocytochemical analyses, as described previously. ${ }^{16,18}$

\section{Grafting hKEpC NCAM1 ${ }^{+}$Cells in NOD/SCID Mice}

$\mathrm{NCAM}^{+}$cells separated by MACS were suspended in 200 $\mu \mathrm{L}$ Matrigel (BD Biosciences) and were injected subcutaneously into NOD/SCID mice (Harlan Laboratories, Israel). At 14 days after injection, the grafts were removed, paraffinembedded, and serially sectioned at $6 \mu \mathrm{m}$ for histological and immunocytochemical analyses.

\section{Induction of Acute Kidney Injury and $\mathrm{NCAM}^{+}{ }^{+}$Cell Injection}

Acute kidney injury (AKI) was induced in female NOD/ SCID mice by intramuscular injection with $50 \%$ hypertonic glycerol (Sigma-Aldrich) solution in water $(9 \mu \mathrm{L} / \mathrm{g}$ body weight) after water deprivation for 22 hours. Controlled intramuscular injection of glycerol into the inferior hind limbs was performed under anesthesia (isoflurane inhalation; Abbott Laboratories, North Chicago, IL). Mice received an intravenous injection into the tail vein at 2 hours after glycerol injection, as follows: group 1, saline $(n=8)$; group $2, \mathrm{NCAM}^{+}$cells $\left(n=7,1.5 \times 10^{6}\right.$ cells; $n=3$, $\left.0.43 \times 10^{6}\right)$; and group 3 , NCAM1 ${ }^{-}$cells $\left(n=7,1.5 \times 10^{6}\right.$ cells; $n=3,0.43 \times 10^{6}$ ). Human adult kidney cells were obtained from three different patients. Blood samples from mice were collected for blood urea nitrogen (BUN) and creatinine measurements at 3 and 14 days after glycerol injection; the animals were then sacrificed.

Animal experiments were performed in adherence to the National Institutes of Health Guide for the Care and Use of Laboratory Animals (8th edition, 2011), after approval by the Institutional Animal Care and Use Committee.

\section{Immunotoxin (huN901-DM1) Assay in Vivo}

BALB/c mice (Harlan Laboratories) received an intravenous injection into the tail vein 2 hours after glycerol injection, as follows: group 1 , saline $(n=10)$; group 2, huN901-DM1 $(18 \mu \mathrm{g} / \mathrm{g} ; n=10)$; and group 3 , huN901(18 $\mu \mathrm{g} / \mathrm{g} ; n=10)$. Blood samples from mice were collected for creatinine measurements at 3 days after glycerol injection; the animals were then sacrificed.

For NCAM1 staining, mouse kidneys were harvested at 3 days after glycerol injection, paraffin-embedded, and serially sectioned at $6 \mu \mathrm{m}$ for immunofluorescence analysis with antiNCAM1 antibody (Epitomics, Burlingame, CA). For FACS analysis, injured mouse kidneys were soaked in collagenase for 1 hour and the cells were stained with huN901 and humanIgG-fluorescein isothiocyanate (Abcam, Cambridge, MA).

\section{Genetic Cell Labeling}

To establish genetically marked hKEpCs, HEK293 cells were initially transformed. HEK293 cells were maintained in DMEM supplemented with $10 \%$ fetal calf serum, L-glutamine, penicillin, and streptomycin (Biological Industries, Beit-Ha'emek, Israel), at $37^{\circ} \mathrm{C}$ in a $5 \% \mathrm{CO}_{2}$-enriched atmosphere. Cells were transfected using calcium phosphate with three lentiviral vectors: $7.5 \mu \mathrm{g}$ pHR-CMV-mCherry, 5 $\mu \mathrm{g} \Delta \mathrm{R} 8.2$, and $2.5 \mu \mathrm{g}$ pMD2.G. After 6 hours, the supernatants were replaced with $5 \mathrm{~mL}$ of fresh medium. Supernatants of transfected cells were supplemented with HEPES (pH 7.0; $50 \mathrm{mmol} / \mathrm{L}$ final concentration) and filtered through a 0.45 $\mu \mathrm{m}$ pore-size filter; $2 \mathrm{~mL}$ was placed on the targeted cells for 2 hours with the addition of $8 \mu \mathrm{g} / \mathrm{mL}$ Polybrene (hexadimethrine bromide; Sigma-Aldrich), and then $3 \mathrm{~mL}$ of fresh medium was added. These viral-like particles were used to infect hKEpCs $\left(2 \times 10^{5}\right.$ cells in 60 -mm-diameter dishes $)$. Expression of the mCherry reporter gene was analyzed at 2 days after infection. 
A

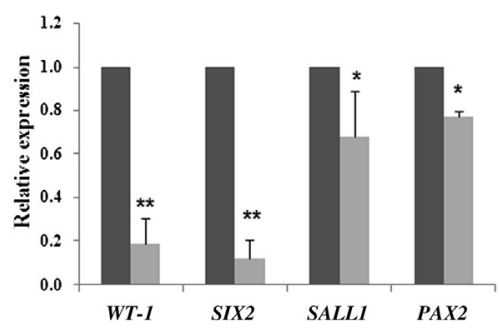

C

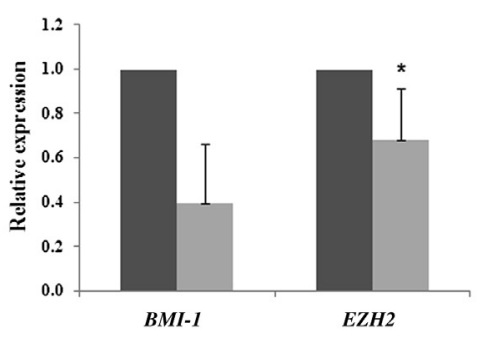

B

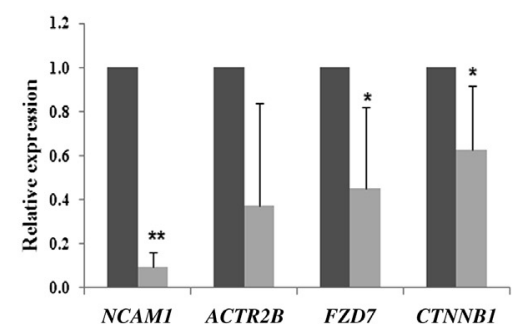

D

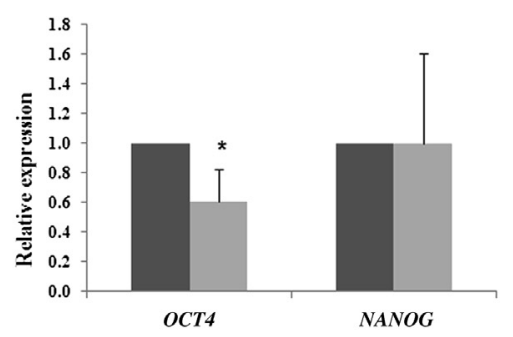

Figure 1 Gene expression analysis of $\mathrm{NCAM1}^{+}$ (dark gray bars) versus NCAM1- (light gray bars) cell fractions. A: Nephron progenitor genes (PAX2, SIX2, SALL1, WT1). B: Genes of the Wnt pathway (CTNNB1, FZD7) and embryonic renal progenitor surface marker genes (ACTR2B, FZD7, NCAM1). C: Polycomb group genes (BMI1, EZH2). D: Pluripotency genes [NANOG, POU5F1 (OCT4)]. E: Renal differentiation marker genes [vimentin (VIM), E-cadherin (CDH1), $\mathrm{Na} / \mathrm{Cl}$ cotransporter (NCCT), aminopeptidase $A(E N P E P)$, and aquaporins 1 and 3 $(A Q P 1, A Q P 3)]$. Differences in aquaporins 1 and 3 approached statistical significance $(P=0.06)$. Data are expressed as means \pm SEM of at least three different experiments on human adult kidney from three different patients. ${ }^{*} P<0.05,{ }^{*} P<0.01$.

\section{$\mathbf{E}$}

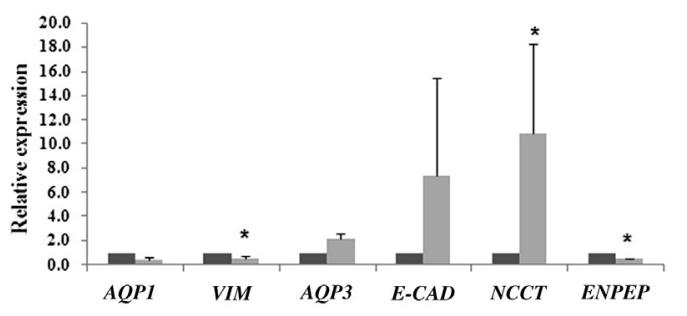

\section{Human Cell Tracing in Mouse Kidney}

mCherry-labeled hKEpCs were injected intravenously into NOD/SCID mice via the tail vein at 2 hours after glycerolinduced AKI. At 24 hours after cell injection, the animals were sacrificed. Both kidneys were surgically removed and were immediately analyzed with a CRi Maestro II in vivo imaging system (Caliper Life Sciences, Hopkinton, MA). Fluorescence images were obtained with an excitation wavelength of $465 \mathrm{~nm}$ and emission wavelength range of 500 to $800 \mathrm{~nm}$.

\section{RT-PCR of the Mouse Kidneys}

RNA was isolated from the dissected kidneys using TRIzol reagent (Life Technologies) and then was reversetranscribed as described above. Quantitative PCR was performed using a qPCR system for hGAPDH and $m \beta$-actin, using gene-specific TaqMan gene expression assay premade kits (Life Technologies). The PCR products were analyzed by electrophoresis in $2.5 \%$ agarose gel and visualized by ethidium bromide staining.

\section{Statistical Analysis}

Statistical differences between two groups of data were compared by Student's $t$-test. For all statistical analyses, the level of significance was set as $P<0.05$. Except as otherwise indicated, data are expressed as means \pm SEM.

\section{Results}

\section{NCAM1 Is Activated in Proliferative hKEpC}

After the retrieval of a small specimen of human adult kidney tissue from nephrectomized patients, tissue was dissociated into a single-cell suspension and cultured at low densities (approximately $1 \mathrm{cell} / \mathrm{cm}^{2}$ ) under adherent conditions in T75 flasks, to enhance clonal growth of hKEpCs. ${ }^{16}$ Proliferative hKEpCs comprise several types of kidney epithelia. To determine whether proliferative hKEpCs express NCAM1 after reaching confluence, despite a lack of in situ expression in renal epithelia, we performed FACS analysis and found $15.9 \pm 9.1 \%$ NCAM1 staining. Previous analysis has shown that putative renal stem-cell surface antigens CD24 and CD133, ${ }^{19,20}$ as well as the epithelial differentiation marker EpCAM, are widely expressed in proliferative $\mathrm{hKEpC}^{12}$ and therefore represent the entire growing culture, rather than a cell subset such as NCAM1.

\section{NCAM $1^{+}$Cells Overexpress Renal Progenitor Markers}

Having determined that proliferative hKEpCs can be stimulated to express NCAM1, we characterized sorted NCAM1 ${ }^{+}$ 


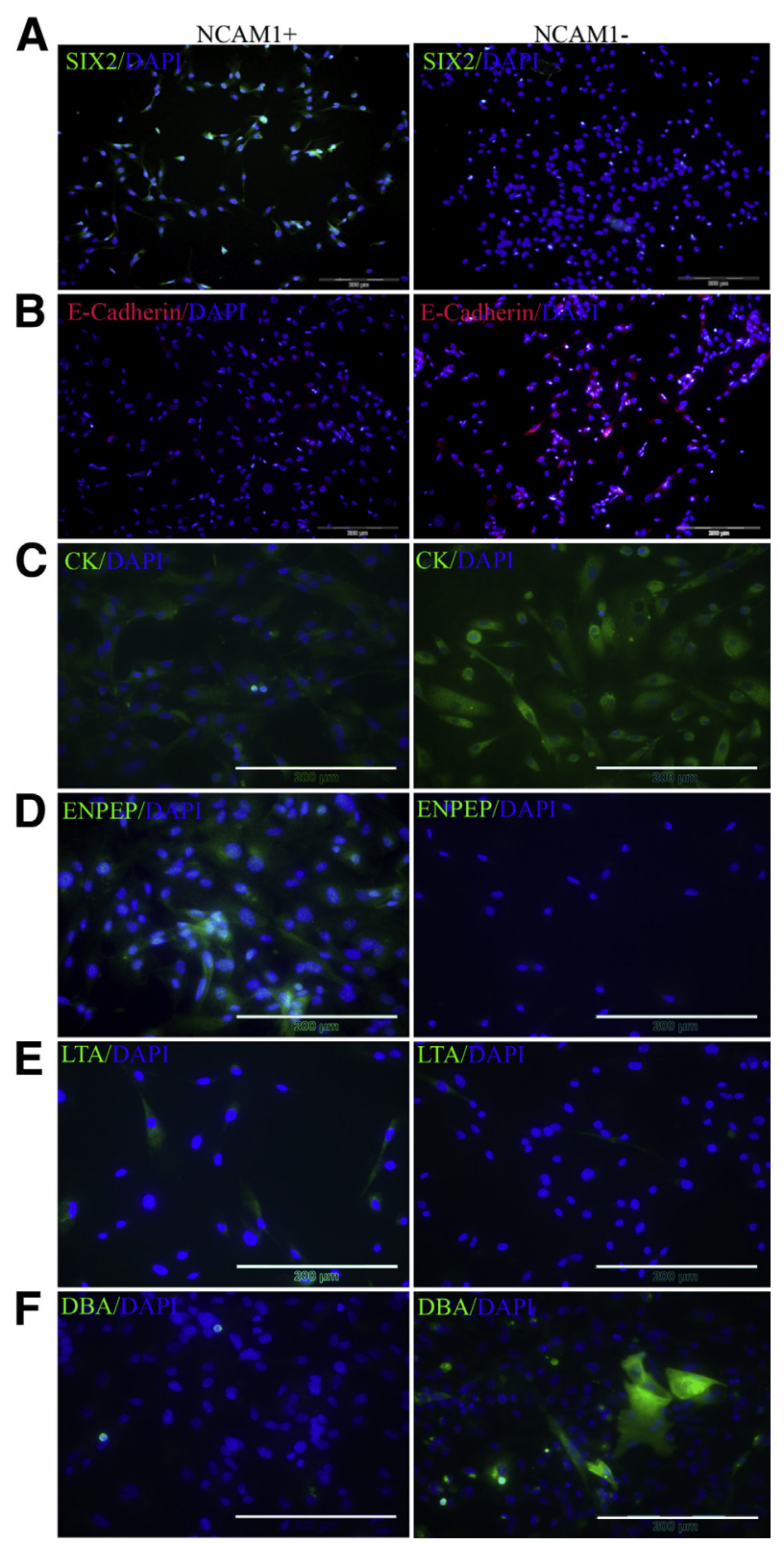

Figure 2 Expression of nephron segment-specific markers in $\mathrm{NCAM1}^{+}$ and NCAM1 ${ }^{-}$cell culture in representative micrographs of immunofluorescent staining of cell cultures at 1 day after separation. A: SIX2. B: E-cadherin. C: Cytokeratin (CK). D: Aminopeptidase A (ENPEP). E: LTA. F: DBA. Positively stained cells are green or red; nuclei are stained with DAPI (blue). Scale bar $=200 \mu \mathrm{m}$. Original magnification, $\times 20$.

cells (Supplemental Figure S1) by qPCR for the expression of the following markers associated with renal stemness ${ }^{10,21}$ : early nephron progenitors (SIX2, SALL1, PAX2, and WT1) (Figure 1A), early surface antigens (FZD7, ACVR2B) (Figure 1B), ${ }^{11}$ polycomb group (BMI1, EZH2) (Figure 1C), Wnt pathway ( $\beta$-catenin, FZD7) (Figure 1B), and the pluripotency and reprogramming factor POU5F1 (alias OCT4) (Figure 1D). Analysis of proliferative hKEpCs generated from adult kidney from five different patients indicated significant overexpression of these genes in $\mathrm{NCAM}^{+}$cells, compared with the negative fraction. Concomitantly, we observed high vimentin $(V I M)$ and low E-cadherin $(\mathrm{CDHI})$ levels in $\mathrm{NCAM}^{+}$cells (Figure 1E), indicative of a more mesenchymal fate simulating earlier stages of renal development.

To test whether $\mathrm{NCAM}^{+}$cells retain differentiation markers, we analyzed expression of markers that indicate various mature nephron compartments (Figure 1E). qPCR revealed elevated aminopeptidase $\mathrm{A}$ (ENPEP) and aquaporin $1(A Q P 1)$ levels and low sodium/chloride cotransporter (SLC12A3; alias NCCT) and aquaporin 3 (AQP3) expression, indicating that $\mathrm{NCAM}^{+}{ }^{+}$cells most likely originate from the proximal tubule. Further interrogation of $\mathrm{NCAM}^{+}$cells by immunofluorescence indicated enhanced SIX2 expression, as well as reduced levels of E-cadherin and pan-cytokeratin, compared with $\mathrm{NCAM}^{-}$cells. Immunostaining of ENPEP and to a lesser extent LTA (proximal tubule markers), but not DBA (a marker of distal and collecting tubules), was more prominent in $\mathrm{NCAM}^{+}$cells (Figure 2). Thus, a distinct lineage in proliferative hKEpCs may be activated to acquire progenitor markers.

\section{Global Transcriptional Changes in NCAM1 ${ }^{+}$Cells Show Reduced Expression of Genes Characteristic of Kidney Differentiation}

Having identified specific characteristics of $\mathrm{NCAM}^{+}$cells, we aimed to assess at a global level the transcriptional changes taking place after separation, based on NCAM1 expression. For this purpose, we separated $\mathrm{NCAM}^{+}$and NCAM1 ${ }^{-}$populations and compared their global gene expression profile using oligonucleotide microarrays. Unsupervised clustering (Partek Genomic Suite version 6.5) of the entire human microarray data set clearly distinguished between the two groups, indicating a different biological entity and fundamental difference in gene expression patterns (Figure 3). We identified 316 genes differentially expressed

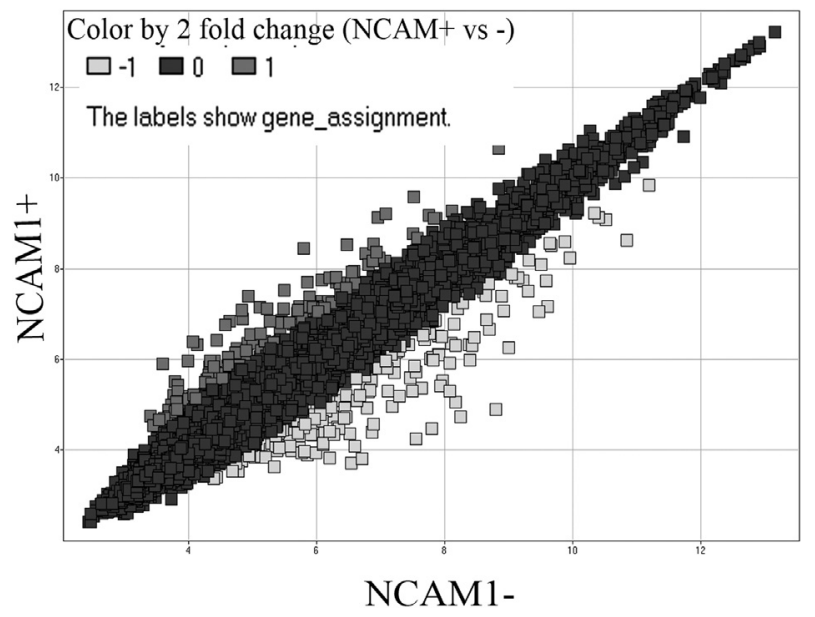

Figure 3 Microarray analysis of $\mathrm{NCAM}^{+}$versus $\mathrm{NCAM}^{-}$fractions of hKEpCs. Scatter plot of differentially expressed genes, those that were either up-regulated (142 genes) or down-regulated (174 genes) in the $\mathrm{NCAM}^{+}$cell fraction at least twofold, compared with the $\mathrm{NCAM}^{-}$cell fraction. 
Table 1 Gene Ontology Annotations for Up- and DownRegulated Genes in the NCAM1 ${ }^{+}$versus NCAM1 ${ }^{-}$Subpopulations

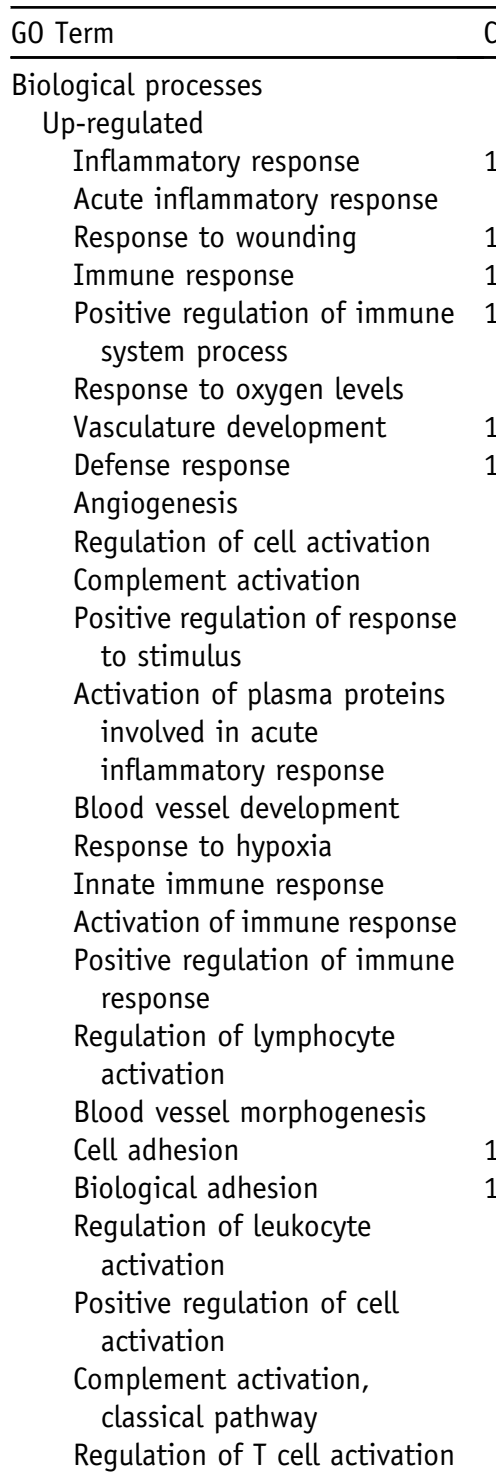

Down-regulated

Cell adhesion

Biological adhesion

Ectoderm development

Defense response

Epidermis development

Immune response

Taxis

Chemotaxis

Inflammatory response

Lymphocyte chemotaxis

Leukocyte migration

Cell-substrate adhesion

Positive regulation of cell adhesion

Molecular function

Up-regulated

Water transporter activity

Calcium ion binding

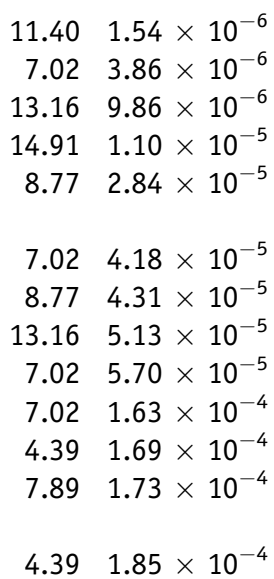

$7.892 .23 \times 10^{-4}$

$6.142 .66 \times 10^{-4}$

$6.143 .12 \times 10^{-4}$

$5.264 .01 \times 10^{-4}$

$6.144 .06 \times 10^{-4}$

$6.144 .53 \times 10^{-4}$

$7.025 .08 \times 10^{-4}$

$12.287 .04 \times 10^{-4}$

$12.287 .13 \times 10^{-4}$

$6.148 .30 \times 10^{-4}$

$5.268 .58 \times 10^{-4}$

$3.519 .18 \times 10^{-4}$

$5.26 \quad 0.00109$

$13.826 .92 \times 10^{-6}$

$13.827 .07 \times 10^{-6}$

$6.581 .01 \times 10^{-4}$

$11.181 .87 \times 10^{-4}$

$5.923 .22 \times 10^{-4}$

$11.186 .67 \times 10^{-4}$

$5.267 .39 \times 10^{-4}$

$5.267 .39 \times 10^{-4}$

$7.249 .16 \times 10^{-4}$

$\begin{array}{ll}1.97 & 0.00175\end{array}$

$3.29 \quad 0.00194$

$\begin{array}{ll}3.95 & 0.0022\end{array}$

3.290 .00234

$3.518 .19 \times 10^{-5}$

$14.914 .02 \times 10^{-4}$

(table continues)
Table 1 (continued)

\begin{tabular}{lccl}
\hline G0 Term & Count & $\%$ & $P$ value \\
\hline Water channel activity & 3 & 2.63 & 0.00287 \\
Integrin binding & 4 & 3.51 & 0.00744 \\
RNA polymerase II & 3 & 2.63 & 0.02862
\end{tabular}

transcription factor activity,

enhancer binding

GPI anchor binding

Protein complex binding

Solute:solute antiporter activity

Symporter activity

Wide pore channel activity

Endopeptidase inhibitor activity

Antiporter activity

Peptidase activity, acting on

L-amino peptides

Peptidase inhibitor activity

Polysaccharide binding

Pattern binding

Amine transmembrane

transporter activity

Peptidase activity

Glucose transmembrane

transporter activity

Down-regulated: None

Cellular components

Up-regulated

Extracellular region part

Extracellular region

Extracellular matrix

Proteinaceous extracellular matrix

Extracellular space

Platelet alpha granule lumen

Cytoplasmic membrane-

bounded vesicle lumen

Vesicle lumen

Platelet alpha granule

Extracellular matrix part

Down-regulated

Extracellular region

Plasma membrane part

Extracellular region part

Extracellular space

Plasma membrane

Tight junction

Occluding junction

Integral to plasma membrane

Intrinsic to plasma membrane

High-density lipoprotein particle

$\begin{array}{lll}2 & 1.75 & 0.03344 \\ 5 & 4.39 & 0.04409 \\ 3 & 2.63 & 0.05179 \\ 4 & 3.51 & 0.06605 \\ 2 & 1.75 & 0.07211 \\ 4 & 3.51 & 0.0755 \\ 3 & 2.63 & 0.07764 \\ 8 & 7.02 & 0.07859 \\ & & \\ 4 & 3.51 & 0.08552 \\ 4 & 3.51 & 0.08681 \\ 4 & 3.51 & 0.08681 \\ 3 & 2.63 & 0.08973 \\ & & \\ 8 & 7.02 & 0.09416 \\ 2 & 1.75 & 0.09704\end{array}$

$\begin{array}{ll}1.75 & 0.03344\end{array}$

3.510 .06605

1.750 .07211

3.510 .0755

$\begin{array}{ll}2.63 & 0.07764\end{array}$

$\begin{array}{ll}3.51 \quad 0.08552 \\ 3.51 & 0.08681\end{array}$

$\begin{array}{ll}3.51 & 0.08681\end{array}$

$\begin{array}{ll}3.51 & 0.08681\end{array}$

$\begin{array}{ll}7.02 & 0.09416\end{array}$

\section{.}


up-regulated genes and the 20 most down-regulated genes are listed in Supplemental Table S1.

To infer the function of the 316 differentially expressed genes, we used the Gene Ontology (GO) enrichment analysis tool and DAVID. The results provided compelling evidence for epithelial dedifferentiation and EMT, including down-regulation of E-cadherin, various keratins (KRT7, KRT81, and KRT34), and tight junction genes (CLDN16, CLDN7, OCLN, CGN, MARVELD2, CLDN3), all indicating epithelial development. Consistently, we detected strong down-regulation of RBM35A (now reclassified as ESRP1, epithelial splicing regulatory protein 1). Recently, the activation of the FGFR2/RBM35A signaling pathway has been shown to maintain epithelial integrity and be critical for regulating the EMT phenotype. ${ }^{22,23}$ In addition, cell adhesion molecules were mostly down-regulated in $\mathrm{NCAM}^{+}$ cells, whereas $W N T 5 B$, which provides permissive cues for cell movement during development, was up-regulated, ${ }^{24-27}$ suggesting enhanced migratory capacity of dedifferentiated cells.

The $\mathrm{NCAM}^{+}$fraction showed up-regulation of a variety of functional proteins (eg, ion channels, water transporter activity) (Table 1). Close examination of this group revealed genes that specify proximal tubular function [bicarbonate (SLC4A4), phosphate (SLC34A2), glucose
(SLC2A9, SLC2A3), urea (SLC14A1), and cationic amino acid (SLC7A7) transporters/cotransporters, as well as aminopeptidase A (ENPEP), aquaporin $1(A Q P 1)$, and carbonic anhydrase IX (CA9)], reaffirming a proximal origin of $\mathrm{NCAM}^{+}{ }^{+}$cells. Finally, we observed up-regulation of gene groups that function in immune modulation and angiogenesis, which may be beneficial in the context of cell therapy (Table 1). Moreover, most transcriptional changes in our data set were noted in genes that regulate the extracellular compartment and may influence tissue remodeling (Table 1) (DAVID) $(P<0.00001)$.

\section{$\mathrm{NCAM}^{+}$Cells Exhibit Robust Clonogenicity, Mesenchymal Differentiation, Sphere-Formation Capacity, and Retain Ability to Produce Renal Epithelial Tissue}

We next tested whether NCAM-expressing cells can be distinguished by in vitro stem/progenitor assays. Calibration experiments showed that hKEpCs cultured with human FKCM harbor enhanced clonogenic capacity (Supplemental Figure S2). We therefore assessed clonogenic potential by cloning single isolated $\mathrm{NCAM}^{+}$and $\mathrm{NCAM}^{-}{ }^{-}$cells under these conditions in 96-well plates. Experiments were
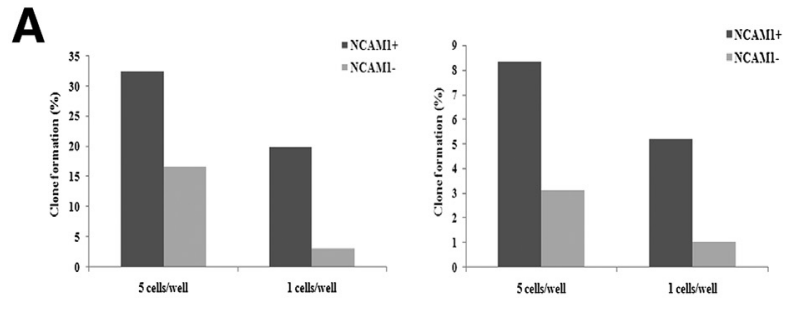

C

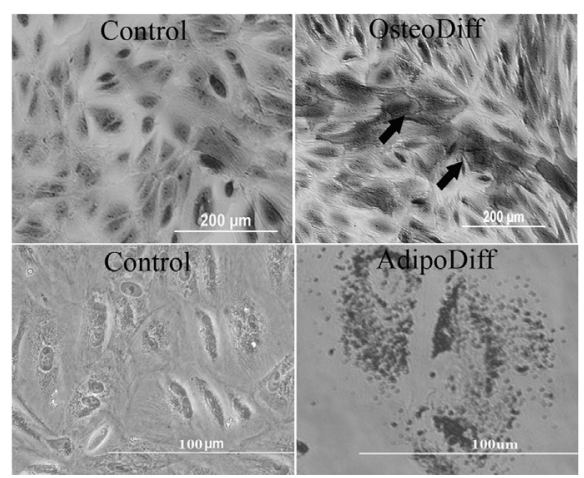

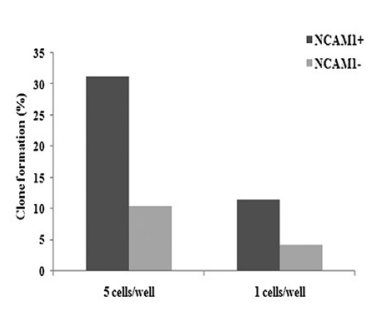

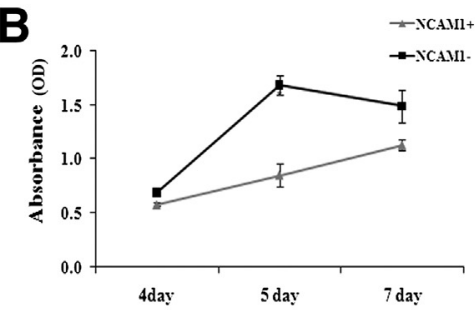

D

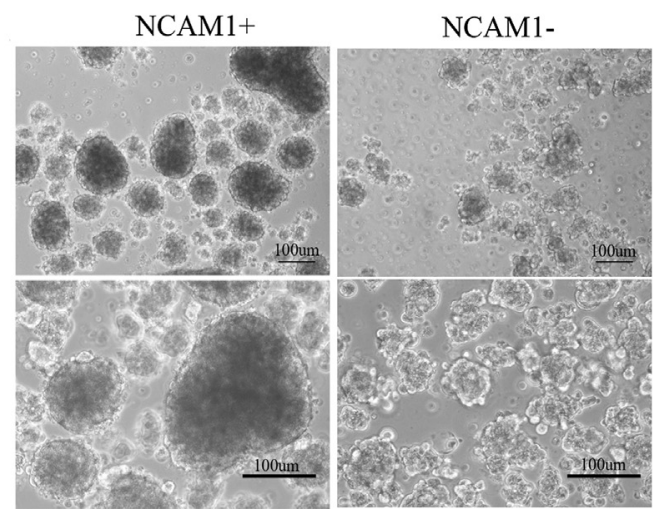

Figure 4 Functional analysis of $\mathrm{NCAM}^{+}$and $\mathrm{NCAM}^{-}$cells in vitro. A: Sorted human $\mathrm{NCAM1}^{+}$and $\mathrm{NCAM}^{-}$cells were subjected to clone-formation assay performed in FKCM. Both $\mathrm{NCAM}_{1}^{+}$and NCAM1 ${ }^{-}$cells were plated at 1 and 5 cells per well. $\mathrm{NCAM}^{+}$cells exhibited significantly higher clonogenic potential in all concentrations in all three experiments; cells originated from human adult kidney from three different patients. B: Sorted human NCAM1 ${ }^{+}$and NCAM1 ${ }^{-}$cells were subjected to MTS proliferation assay. Both $\mathrm{NCAM}^{+}$and NCAM1 ${ }^{-}$cell fractions were analyzed at 4, 5, and 7 days after sorting. NCAM1 ${ }^{+}$cells exhibited decreased proliferation rates. Data are representative of three experiments performed in triplicate. C: Differentiation of NCAM1 ${ }^{+}$cells into osteoblasts and adipocytes (arrows indicate positive staining). Top row: Representative micrographs of histochemical staining after 10 days in control medium (DMEM) and OsteoDiff medium. Bottom row: Representative micrographs of histochemical staining after 21 days in control medium (DMEM) and AdipoDiff medium. D: Sphere-formation assay. NCAM1 ${ }^{+}$and NCAM1 ${ }^{-}$cells isolated from low-passage cultures expanded in vitro exhibit exclusive capacity of the NCAM1 ${ }^{+}$fraction to form well-defined spheres after 7 days under low-attachment culture conditions. Data are expressed as means \pm SEM. Scale bars: $200 \mu \mathrm{m}$ (C, top row); $100 \mu \mathrm{m}$ (C, bottom row, and D). Original magnification: $\times 10$ (C, top row); $\times 20$ (C, bottom row, and $\mathbf{D})$. ${ }^{\star} P<0.05 .0 \mathrm{D}$, optical density. 

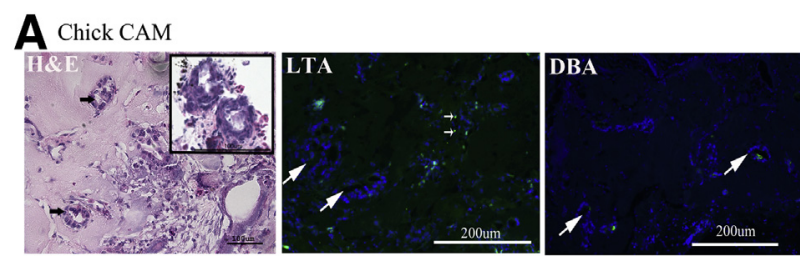

B NOD/SCID

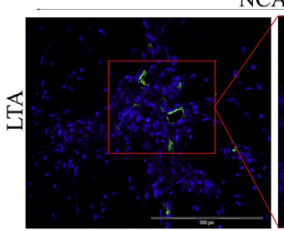

NCAM1+
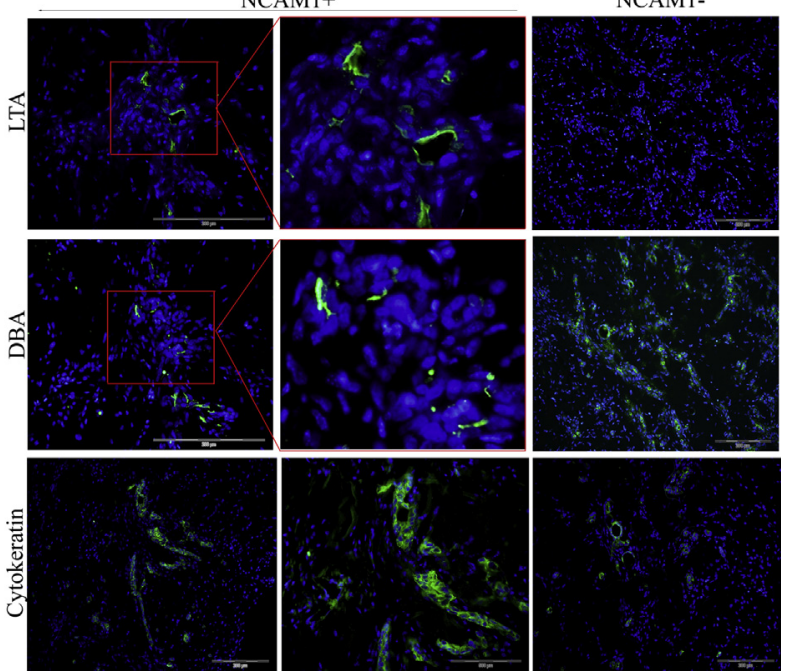

Figure 5 In vivo analysis of sorted human $\mathrm{NCAM}^{+}$cells. Sorted NCAM1 $1^{+}$cells $\left(0.43 \times 10^{6}\right)$ were grafted onto the chick CAM and assessed after 7 days. A: H\&E staining of the grafts reveals tubular formation. LTA staining is positive (green) in unorganized cells (small arrows); no positive staining was detected in organized tubules (large arrows). No DBA staining was detected in tubules (arrows) or other structures. Nuclei were stained with DAPI (blue). Boxed regions are shown at higher magnification in the corresponding middle panels. B: $\mathrm{NCAM}^{+}$and $\mathrm{NCAM}^{-}{ }^{-}$cells were injected subcutaneously into NOD/SCID mice and grafts were analyzed at 2 weeks after transplantation. Analysis of renal structures for expression of segment-specific antibodies reveals positive staining for LTA staining only in grafts derived from $\mathrm{NCAM}^{+}$cells, but positive staining of DBA and cytokeratin in both $\mathrm{NCAM}^{+}$and $\mathrm{NCAM1}^{-}$grafts. Scale bars: $100 \mu \mathrm{m}$ (A, right); $200 \mu \mathrm{m}$ (A, middle and left; $\mathbf{B}$, left and right).

performed using cells from three different patients. Of the single $\mathrm{NCAM}^{+}$cells, $3 \%$ to $16 \%$ divided and eventually filled the culture well with a confluent monolayer, whereas the majority of single NCAM1 ${ }^{-}$cells did not (Figure 4A). Interestingly, a parallel analysis of proliferation rate using the MTS assay indicated reduced proliferation in $\mathrm{NCAM} 1^{+}$ cells (Figure 4B), indicating the highly clonogenic, slowcycling nature of the cells. Proliferative hKEpCs grown under low-attachment conditions have been shown to produce kidney-spheres that elevate E-cadherin and recapitulate functioning kidney epithelial organoids. ${ }^{16}$ It was therefore interesting to determine whether $\mathrm{NCAM}^{+}$cells, which harbor propensity to a mesenchymal fate (high vimentin, low E-cadherin) (Figure 1E), as well as forced adipogenic and osteogenic differentiation with inductive culture medium (Figure 4C), exhibit this in vitro capacity. Immediately after sorting of low-passage cultures (P2), only $\mathrm{NCAM}^{+}$cells generated kidney-spheres/organoids, whereas the $\mathrm{NCAM} 1^{-}$fraction was devoid of this capacity (Figure 4D), suggesting that $\mathrm{NCAM}^{+}$cells, although deviating toward mesenchyme, maintain in vitro plasticity and epithelial fate.

We further analyzed whether dedifferentiated $\mathrm{NCAM} 1^{+}$ could also redifferentiate to generate epithelial structures in vivo and grafted cells in the chick CAM assay and on transplantation into the subcutaneous space of NOD/SCID mice. Importantly, multipotential mesenchymal cells were completely devoid of tubulogenic potential on CAM grafting. ${ }^{16}$ After 1 week, implantation of $0.43 \times 10^{6} \mathrm{NCAM}^{+}$ cells into the CAM revealed large, well-defined grafts (Supplemental Figure S3A). H\&E staining of graft sections revealed extensive morphogenesis into tubular structures (Figure 5A). These tubular structures did not express segment-specific kidney maturation markers (cytokeratin/ MNF116, LTA, DBA). These markers appear only at late stages of human kidney development in differentiated structures (Supplemental Figure S3, C and D). Therefore, after dedifferentiation, the observed robust redifferentiation capacity of $\mathrm{NCAM}^{+}$cells on the chick CAM may follow developmental MET, leading initially to generation of primitive tubular structures (devoid of maturation markers) reminiscent of early kidney development. In contrast to $\mathrm{NCAM}^{+}{ }^{+}$cells, less dedifferentiated NCAM1 ${ }^{-}$cells were found to generate $\mathrm{DBA}^{+}$tubule structures after 1 week (Supplemental Figure S3B). Because the CAM model has a 1-week time limit for analysis, we used grafts developed in the NOD/SCID mouse for a 2-week period. At 2 weeks, $\mathrm{NCAM}^{+}$cells reconstituted differentiated human cytokeratin $^{+}$tubules (Figure 5B) and could generate both $\mathrm{LTA}^{+}$and $\mathrm{DBA}^{+}$type proximal and distal tubules, in contrast with $\mathrm{NCAM}^{-}$cells, which were again found to generate only $\mathrm{DBA}^{+}$tubules (Figure $5 \mathrm{~B}$ ). Thus, dedifferentiation of $\mathrm{NCAM}^{+}$cells in vitro may lead in turn to a wider renal potential on grafting in vivo.

\section{In Vitro and in Vivo Treatment with Anti-NCAM Antibody Drug Conjugate}

We next analyzed the effects of depletion of $\mathrm{NCAM}^{+}$cells using an anti-NCAM antibody drug conjugate (NCAMADC; N901 antibody conjugated to cytotoxic DM1). Initially, we calibrated the cell concentration and ADC concentration required to deplete $\mathrm{NCAM}^{+}$cells from proliferative hKEpC cultures (Supplemental Figure S4). As seen from a representative FACS analysis, treatment with NCAM-ADC decreased NCAM1 expression (Figure 6A). Additionally, the MTS proliferation assay showed diminished cell proliferation after ADC treatment, as a result of cell death caused by the immunoconjugate (Figure 6B). Clonogenic capacity and sphere-forming ability of NCAMADC-treated cultures were decreased, compared with untreated cells and cells treated with antibody alone (Figure 6, C and D), indicating that depletion of NCAM1 ${ }^{+}$ cells in hKEpCs significantly abrogates stemness traits. 
A

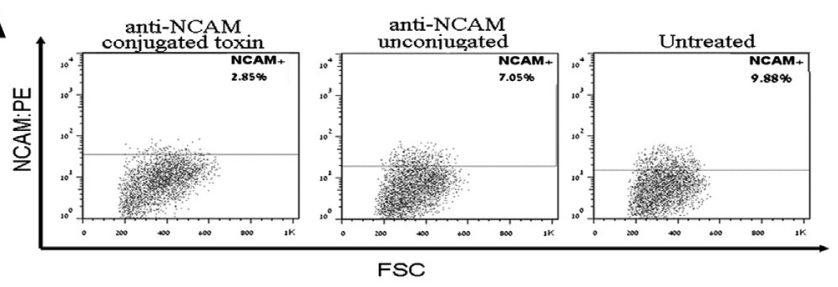

B

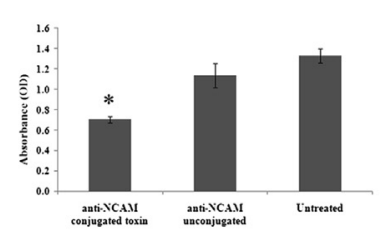

D
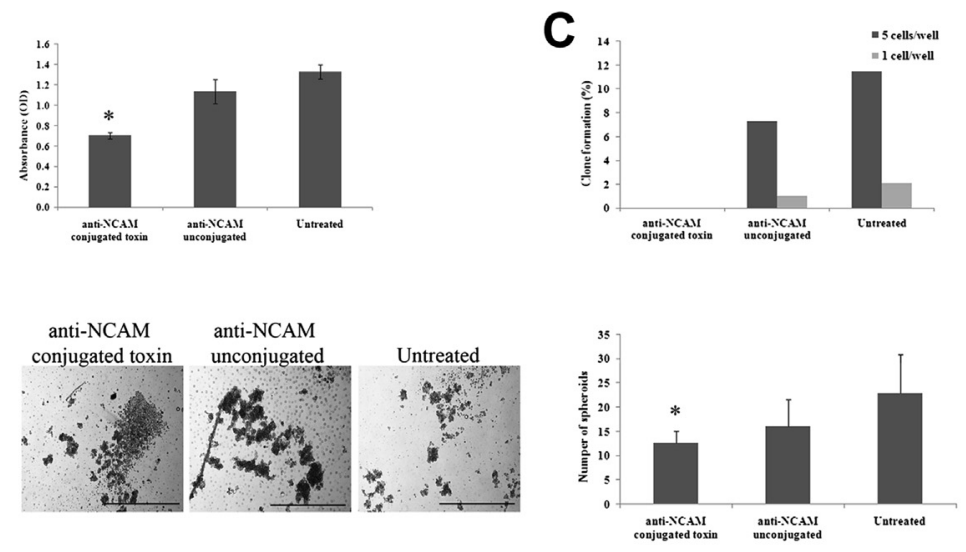

$\mathbf{E}$

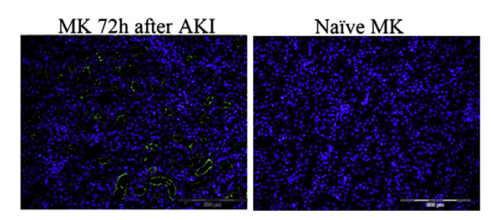

$\mathbf{F}$

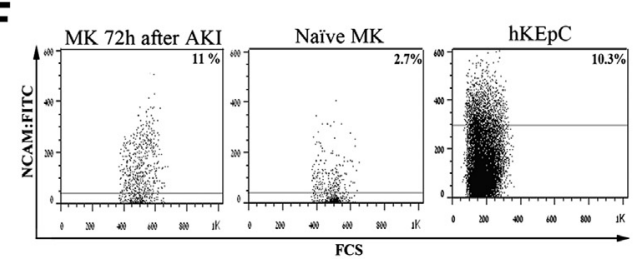

G

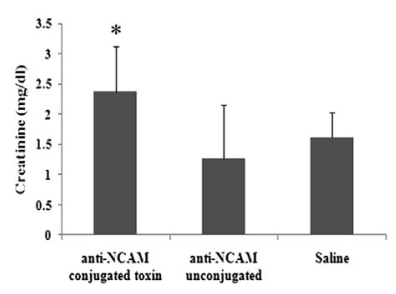

Figure 6 Treatment with anti-NCAM conjugated toxin: hKEpCs treated with anti-NCAM conjugated toxin antibody (huN901-DM1), unconjugated anti-NCAM (huN901) antibody, compared with untreated hKEpCs. A: FACS analysis from a representative experiment shows an approximately $30 \%$ decrease in NCAM1 expression caused by anti-NCAM conjugated toxin treatment, compared with untreated hKEpCs. Gates were determined according to isotype control in each treatment group separately. B: MTS proliferation assay on day 5 of toxin treatment shows a decrease in cell number in the anti-NCAM conjugated toxin antibody treated group. C: Clone-formation assay from a representative experiment shows the antiNCAM conjugated toxin treatment of hKEpCs abolishes clone-formation capacity, in contrast to control and anti-NCAM unconjugated treated groups. D: Sphere-formation assay (left) shows decreased sphere-formation capacity by hKEpCs treated with the anti-NCAM conjugated toxin, compared with the control and unconjugated antiNCAM antibody treatment. Sphere numbers were quantified (right) for each treatment group. E: Mouse kidney staining at 72 hours after glycerol injection shows elevation in NCAM1 endogenous levels, compared with naïve mouse kidney. F: FACS analysis of NCAM1 expression shows elevation in NCAM1 levels and binding of the antibody to the mouse cells in injured (AKI) mouse kidney, compared with naïve mouse kidney and hKEpCs using huN901 antibody. G: Creatinine blood levels after intravenous administration of the anti-NCAM conjugated toxin to the BALB/c mice 2 hours after glycerol injection. At 72 hours, the creatinine levels are significantly higher, compared with controls. Importantly, unconjugated NCAM N901 antibody, which does not eliminate NCAM1 ${ }^{+}$cells, counteracts effects of anti-NCAM conjugated toxin, significantly reducing peak renal injury at 72 hours. Data are expressed as means \pm SEM of at least three different experiments on three different hKEpCs. ${ }^{*} P<0.05$. Scale bars: $200 \mu \mathrm{m}$ (D and E). MK, mouse kidney; OD, optical density.
Although NCAM1 is not expressed in the resting mature nephron, it reappears in scattered proximal tubular cells after AKI. ${ }^{28}$ We therefore evaluated the consequences of eliminating $\mathrm{NCAM} 1^{+}$cells during a regenerative response. We used the glycerol-induced acute tubular injury model in $\mathrm{BALB} / \mathrm{c}$ mice, in which peak functional renal injury appears 72 hours after glycerol injection and spontaneous recovery occurs thereafter. Similar to our findings for ischemic injury, we found NCAM1 to re-express after toxic tubular injury on the surface of renal epithelia, and up-regulation of NCAM1 levels was readily detected with the NCAM N901 antibody (Figure 6, E and F). NCAMADC was administered 2 hours after glycerol injection and renal function was monitored. At 72 hours, renal function was further significantly compromised, compared with controls. Importantly, unconjugated NCAM N901 antibody, which does not deplete $\mathrm{NCAM}^{+}$cells, counteracted the effects of the NCAM-ADC (Figure 6G).

\section{In Vivo Effects of Human NCAM1 ${ }^{+}$Cells in Glycerol-Induced AKI}

Having established that in situ NCAM targeting can modulate renal function during AKI, we tested the effects of exogenous administration of human $\mathrm{NCAM}^{+}$cells. We calibrated glycerol-induced AKI in NOD/SCID mice and determined a sublethal injection dose of glycerol $(9 \mu \mathrm{L} / \mathrm{g})$ for further experiments. A control group of mice was used to determine basal levels for serum creatinine and BUN in normal NOD/SCID mice $(n=12)$, which averaged $0.37 \pm$ $0.02 \mathrm{mg} / \mathrm{dL}$ and $21.43 \pm 2.37 \mathrm{mg} / \mathrm{dL}$, respectively. Similar to injury in BALB/c mice intramuscular injection of glycerol on day 0 resulted in an increase in creatinine and BUN levels, with peak levels observed at 48 to 72 hours. Thereafter, BUN and creatinine levels declined, and spontaneous recovery was observed after 14 days. Intravenously administered $\mathrm{NCAM}^{+}$cells $(2$ hours after glycerol 

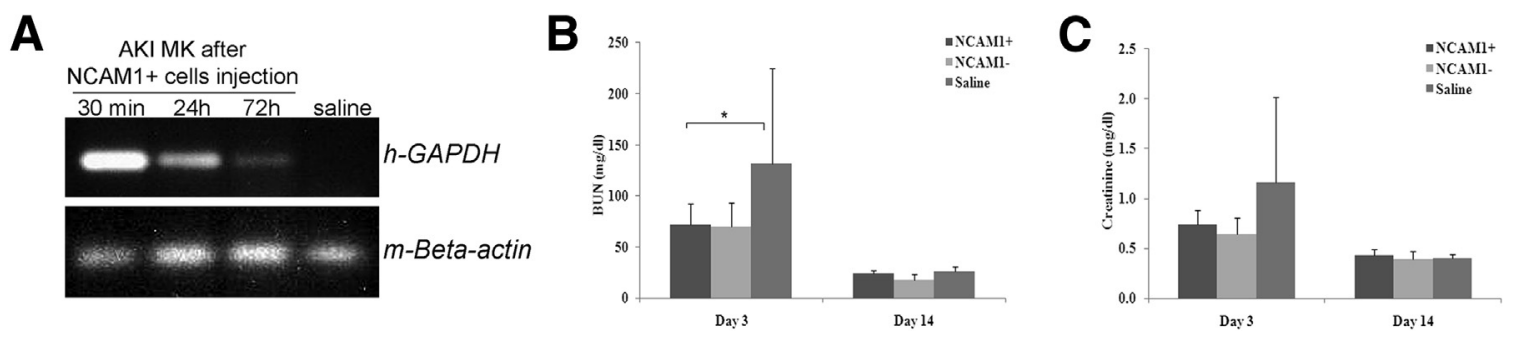

Figure $7 \quad \mathrm{NCAM1}^{+}$cells attenuate BUN and creatinine peaks in AKI. NCAM1 ${ }^{+}, \mathrm{NCAM1}^{-}$cells or saline were injected intravenously 2 hours after glycerol administration. A: RT-PCR of human specific GAPDH (hGAPDH) of saline-treated mouse kidney (MK) and of mouse kidneys at 30 minutes, 24 hours, and 72 hours after injection of $1 \times 10^{6} \mathrm{NCAM}^{+}$cells. Mouse $\beta$-actin was used as a positive control for CDNA presence. Blood samples were taken after 3 and 14 days. B and C: NCAM1 ${ }^{+}$and NCAM1 ${ }^{-}$cells attenuate BUN (B) and creatinine (C) peaks at 3 days, compared with the control (saline) treatment group. The expected spontaneous recovery was observed in all treatment groups at 14 days. Data are expressed as means \pm SEM. ${ }^{*} P<0.05$.

injection) were detected in the kidney at significant amounts within the first 24 hours after injection, but were diminished by day 3 (Figure $7 \mathrm{~A}$ ). NCAM1 ${ }^{+}$cells did not show exclusive tropism for the injured kidney, but were intensively detectable also in the lungs (Supplemental Figure S5). Analysis of BUN and creatinine levels revealed attenuate BUN peaks (Figure 7B) and tend to attenuate creatinine peaks (Figure 7C) at 3 days, compared with saline-treated mice (Figure 7, B and C). However, there was no significant difference between $\mathrm{NCAM}^{+}$and $\mathrm{NCAM}^{-}{ }^{-}$cells with respect to kidney function in AKI (Figure 7, B and C).

\section{Discussion}

Using immunosorting to target the surface marker NCAM1, we identified and characterized a unique population of human kidney stem/progenitor-like cells, which arise from primary cultures of human kidney epithelial cells. This subpopulation could be specifically activated in growing cultures to overexpress embryonic renal stemness markers and could be distinguished in clonal assays, forming large numbers of colonies from single cells in the presence of human FKCM. $\mathrm{NCAM}^{+}$cells promptly reverted to a less differentiated mesenchymal-like cell phenotype, down-regulated the expression of mRNAs encoding epithelial markers such as Ecadherin, and up-regulated mesenchymal marker transcripts, but then redifferentiated into epithelial structures in kidney organoids and on grafting as single-cell suspensions into the chick CAM or mouse. Importantly, targeting NCAM1expressing cells during AKI could modulate disease course.

In embryogenesis, EMT and the reverse process (MET) play central roles. ${ }^{29-31}$ Early in development, for example, mesoderm generated by EMTs develops into multiple tissue types; later in development, mesodermal cells give rise to epithelial organs, such as the kidney, a time frame in which NCAM1 is expressed. The loss of E-cadherin expression during EMT is associated with up-regulation of NCAM1 in human breast epithelia, indicating that NCAM1 is a reliable surface marker to identify cells undergoing this process. ${ }^{32,33}$ One can therefore take advantage of NCAM1 not only to sort out developmental renal progenitors before completion of epithelialization during the embryonic MET process ${ }^{13}$ but also for cells that first emerge during dedifferentiation/EMT in adult human epithelial kidney cells.

When human kidney epithelia are placed in adhesion cultures they are released from normal quiescence to become proliferative hKEpCs. We have repeatedly observed that proliferative hKEpCs, comprising different types of kidney epithelia, are uniformly positive for the CD133/CD24 cell surface markers. CD133/CD24 have been previously suggested as markers of multipotent epithelial stem cells in the kidney. ${ }^{19,20}$ Nevertheless, in vivo genetic fate mapping has brought into question the presence of such multipotent epithelial stem cells. ${ }^{34}$ Moreover, a recent detailed pathological analysis of human kidneys and acute tubular necrosis biopsies suggested, at least for the proximal tubule, that CD133/CD24 are markers of dedifferentiated epithelia rather than a genuine stem cell population. ${ }^{35}$ Thus, in terms of in vitro precursor relationships, CD133/CD24 mark the entire bulk of proliferating hKEpCs (those that assume some degree of dedifferentiation upon growth in culture), whereas NCAM1 represents the subset that has reverted along the EMT axis to behave in many ways similar to tissue stem cells. Thus, as previously reported for breast epithelial cells, ${ }^{36}$ with the present findings we suggest for the first time a link between partial dedifferentiation/EMT and the gain of kidney stem-cell properties leading to a stem/progenitor state in vitro.

Our results are interesting in light of previous studies analyzing the cellular events involved in regeneration of renal tubules in animal models. Differentiated tubular cells are thought to dedifferentiate and proliferate after AKI. After enhanced cell proliferation, transiently dedifferentiated regenerating cells are believed to repopulate the damaged area and then redifferentiate into mature epithelial cells to reconstruct the functional integrity of the nephron (reviewed by Bonventre and Yang ${ }^{37}$ ). This process has been shown to activate developmental programs, including the reappearance of early stem/ progenitor cell markers. ${ }^{9,12,38}$ Accordingly, NCAM1, which is not expressed in the mature nephron, has been shown to be reactivated in the rat after ischemic injury in the $\mathrm{S} 3$ segment of the proximal tubule, an area with a high regenerative response, recapitulating its expression in the developing kidney toward rebuilding the tubule. ${ }^{28} \mathrm{NCAM}^{+}$cells sorted from proliferative hKEpCs and disclosing a proximal tubular origin may 
share similarities with this proximal cell fraction that reexpresses NCAM1 after AKI and is involved in the in vivo regenerative response. Interestingly, the tubular structures developed on the chick CAM at 1 week after grafting of human $\mathrm{NCAM}^{+}$cells were devoid of renal maturation markers, and differentiation into $\mathrm{LTA}^{+}$proximal tubules and additional tubule types (not observed with $\mathrm{NCAM} 1^{-}$counterparts) was apparent at 2 weeks in the SCID model. This unique pattern indicates that, when re-establishing the tubule in situ, transient reversion of $\mathrm{NCAM}^{+}$cells to a presumably early and less committed developmental stage in vitro may be followed by stepwise redifferentiation, mimicking renal ontogeny and conferring a wider renal differentiation potential.

Additional parallels can be drawn from experiments with the NCAM antibody drug conjugated, which afforded the opportunity to analyze the consequences of $\mathrm{NCAM}^{+}$cell depletion, demonstrating both diminished stemness and clonogenic response in vitro and worsening of AKI in vivo. Thus, $\mathrm{NCAM}^{+}$cells activated in vitro to acquire stem/ progenitor cell characters are likely to be important to the regenerative response that follows AKI in vivo and thus represent a target for intervention. The fact that NCAM1 does not express in the resting kidney epithelia further increases its validity as a therapeutic target. Other potential regulators revealed by microarrays to be specific to NCAMexpressing cells include ESRP1 and FGFR2, both of which control developmental pathways and epithelial morphogenesis $^{22,23}$ and as such may serve as interventional targets.

Of note, the beneficial effects of exogenous NCAM1 ${ }^{+}$ cells on renal function in the AKI were not exclusive. This lack of exclusive response may be related to the mode of cell administration; with the intravenous route, distribution of cells to the kidney is very limited, and kidney-derived cells arrive and reside in the lungs. This in turn may preclude the differential action of a specific cell subset that is likely dependent on migration to diseased renal tissue and calls for intra-arterial of direct injection modes of cell administration. In addition, it may very well be that any kidney-derived cell exerts some beneficial effect on exogenous delivery. Importantly, the identification of markers of specific cell subsets that participate in the renal regenerative machinery and their in situ targeting by peptides, antibodies, and small molecules may be a superior strategy to exogenous cell therapy for AKI.

\section{Supplemental Data}

Supplemental material for this article can be found at http://dx.doi.org/10.1016/j.ajpath.2013.07.034.

\section{References}

1. Weissman I: The ISSCR: who are we and where are we going? Cell Stem Cell 2009, 5:151-153

2. Barker $\mathrm{N}$, van de Wetering $\mathrm{M}$, Clevers $\mathrm{H}$ : The intestinal stem cell. Genes Dev 2008, 22:1856-1864
3. Blanpain C, Fuchs E: Epidermal homeostasis: a balancing act of stem cells in the skin. Nat Rev Mol Cell Biol 2009, 10:207-217

4. Kondo M, Wagers AJ, Manz MG, Prohaska SS, Scherer DC, Beilhack GF, Shizuru JA, Weissman IL: Biology of hematopoietic stem cells and progenitors: implications for clinical application. Annu Rev Immunol 2003, 21:759-806

5. Little MH: Regrow or repair: potential regenerative therapies for the kidney. J Am Soc Nephrol 2006, 17:2390-2401

6. Diep CQ, Ma D, Deo RC, Holm TM, Naylor RW, Arora N, Wingert RA, Bollig F, Djordjevic G, Lichman B, Zhu H, Ikenaga T, Ono F, Englert C, Cowan CA, Hukriede NA, Handin RI, Davidson AJ: Identification of adult nephron progenitors capable of kidney regeneration in zebrafish. Nature 2011, 470:95-100

7. Hartman HA, Lai HL, Patterson LT: Cessation of renal morphogenesis in mice. Dev Biol 2007, 310:379-387

8. Pleniceanu O, Harari-Steinberg O, Dekel B: Concise review: kidney stem/progenitor cells: differentiate, sort out, or reprogram? Stem Cells 2010, 28:1649-1660

9. Dekel B, Metsuyanim S, Schmidt-Ott KM, Fridman E, Jacob-Hirsch J, Simon A, Pinthus J, Mor Y, Barasch J, Amariglio N, Reisner Y, Kaminski N, Rechavi G: Multiple imprinted and stemness genes provide a link between normal and tumor progenitor cells of the developing human kidney. Cancer Res 2006, 66:6040-6049

10. Dressler GR: The cellular basis of kidney development. Annu Rev Cell Dev Biol 2006, 22:509-529

11. Rosenblum ND: Developmental biology of the human kidney. Semin Fetal Neonatal Med 2008, 13:125-132

12. Metsuyanim S, Harari-Steinberg O, Buzhor E, Omer D, PodeShakked N, Ben-Hur H, Halperin R, Schneider D, Dekel B: Expression of stem cell markers in the human fetal kidney. PloS One 2009, 4: e6709

13. Harari-Steinberg O, Matsuyanim S, Omer D, Gnatek Y, Gershon R, Pri-Chen S, Ozdemir DD, Lerenthal Y, Noiman T, Ben-Hur $\mathrm{H}$, Vaknin Z, Schneider DF, Aronow BJ, Goldstein RS, Hohenstein P: Indentification of human nephron progenitors capable of generation of kidney structures and functional repair of chronic renal disease. EMBO Mol Med 2013, http://doi.dx.org/10.1002/emmm.201201584 [Epub ahead of print]

14. Pode-Shakked N, Metsuyanim S, Rom-Gross E, Mor Y, Fridman E, Goldstein I, Amariglio N, Rechavi G, Keshet G, Dekel B: Developmental tumourigenesis: NCAM as a putative marker for the malignant renal stem/progenitor cell population. J Cell Mol Med 2009, 13: 1792-1808

15. Pode-Shakked N, Shukrun R, Mark-Danieli M, Tsvetkov P, Bahar S, Pri-Chen S, Goldstein RS, Rom-Gross E, Mor Y, Fridman E, Meir K, Simon A, Magister M, Kaminski N, Goldmacher VS, HarariSteinberg O, Dekel B: The isolation and characterization of renal cancer initiating cells from human Wilms' tumour xenografts unveils new therapeutic targets. EMBO Mol Med 2013, 5:18-37

16. Buzhor E, Harari-Steinberg O, Omer D, Metsuyanim S, JacobHirsch J, Noiman T, Dotan Z, Goldstein RS, Dekel B: Kidney spheroids recapitulate tubular organoids leading to enhanced tubulogenic potency of human kidney-derived cells. Tissue Eng Part A 2011, 17:2305-2319

17. Wang L, Amphlett G, Blättler WA, Lambert JM, Zhang W: Structural characterization of the maytansinoid-monoclonal antibody immunoconjugate, huN901-DM1, by mass spectrometry. Protein Sci 2005, $14: 2436-2446$

18. Noiman T, Buzhor E, Metsuyanim S, Harari-Steinberg O, Morgenshtern C, Dekel B, Goldstein RS: A rapid in vivo assay system for analyzing the organogenetic capacity of human kidney cells. Organogenesis 2011, 7:140-144

19. Bussolati B, Bruno S, Grange C, Buttiglieri S, Deregibus MC, Cantino D, Camussi G: Isolation of renal progenitor cells from adult human kidney. Am J Pathol 2005, 166:545-555

20. Sagrinati C, Netti GS, Mazzinghi B, Lazzeri E, Liotta F, Frosali F, Ronconi E, Meini C, Gacci M, Squecco R, Carini M, Gesualdo L, 
Francini F, Maggi E, Annunziato F, Lasagni L, Serio M, Romagnani S, Romagnani P: Isolation and characterization of multipotent progenitor cells from the Bowman's capsule of adult human kidneys. J Am Soc Nephrol 2006, 17:2443-2456

21. Kuure S, Vuolteenaho R, Vainio S: Kidney morphogenesis: cellular and molecular regulation. Mech Dev 2000, 92:31-45

22. Warzecha CC, Jiang P, Amirikian K, Dittmar KA, Lu H, Shen S, Guo W, Xing Y, Carstens RP: An ESRP-regulated splicing programme is abrogated during the epithelial-mesenchymal transition. EMBO J 2010, 29:3286-3300

23. Warzecha CC, Sato TK, Nabet B, Hogenesch JB, Carstens RP: ESRP1 and ESRP2 are epithelial cell-type-specific regulators of FGFR2 splicing. Mol Cell 2009, 33:591-601

24. Babayeva S, Zilber Y, Torban E: Planar cell polarity pathway regulates actin rearrangement, cell shape, motility, and nephrin distribution in podocytes. Am J Physiol Renal Physiol 2011, 300:F549-F560

25. He F, Xiong W, Yu X, Espinoza-Lewis R, Liu C, Gu S, Nishita M, Suzuki K, Yamada G, Minami Y, Chen Y: Wnt5a regulates directional cell migration and cell proliferation via Ror2-mediated noncanonical pathway in mammalian palate development. Development 2008, 135: 3871-3879

26. Lin S, Baye LM, Westfall TA, Slusarski DC: Wnt5b-Ryk pathway provides directional signals to regulate gastrulation movement. J Cell Biol 2010, 190:263-278

27. Nomachi A, Nishita M, Inaba D, Enomoto M, Hamasaki M, Minami Y: Receptor tyrosine kinase Ror2 mediates Wnt5a-induced polarized cell migration by activating c-Jun $\mathrm{N}$-terminal kinase via actin-binding protein filamin A. J Biol Chem 2008, 283:27973-27981

28. Abbate M, Brown D, Bonventre JV: Expression of NCAM recapitulates tubulogenic development in kidneys recovering from acute ischemia. Am J Physiol Renal Physiol 1999, 277:F454-F463

29. Hay ED: An overview of epithelio-mesenchymal transformation. Acta Anat (Basel) 1995, 154:8-20
30. Pérez-Pomares JM, Muñoz-Chápuli R: Epithelial-mesenchymal transitions: a mesodermal cell strategy for evolutive innovation in metazoans. Anat Rec 2002, 268:343-351

31. Thiery JP, Sleeman JP: Complex networks orchestrate epithelialmesenchymal transitions. Nat Rev Mol Cell Biol 2006, 7:131-142

32. Lehembre F, Yilmaz M, Wicki A, Schomber T, Strittmatter K, Ziegler D, Kren A, Went P, Derksen PWB, Berns A, Jonkers J, Christofori G: NCAM-induced focal adhesion assembly: a functional switch upon loss of E-cadherin. EMBO J 2008, 27:2603-2615

33. Evseenko D, Zhu Y, Schenke-Layland K, Kuo J, Latour B, Ge S, Scholes J, Dravid G, Li X, MacLellan WR, Crooks GM: Mapping the first stages of mesoderm commitment during differentiation of human embryonic stem cells. Proc Natl Acad Sci USA 2010, 107:13742-13747

34. Humphreys BD, Czerniak S, DiRocco DP, Hasnain W, Cheema R, Bonventre JV: Repair of injured proximal tubule does not involve specialized progenitors. Proc Natl Acad Sci USA 2011, 108: 9226-9231

35. Smeets B, Boor P, Dijkman H, Sharma SV, Jirak P, Mooren F, Berger K, Bornemann J, Gelman IH, Floege J, van der Vlag J, Wetzels JF, Moeller MJ: Proximal tubular cells contain a phenotypically distinct, scattered cell population involved in tubular regeneration. J Pathol 2013, 229:645-659

36. Mani SA, Guo W, Liao MJ, Eaton EN, Ayyanan A, Zhou AY, Brooks M, Reinhard F, Zhang CC, Shipitsin M, Campbell LL, Polyak K, Brisken C, Yang J, Weinberg RA: The epithelialmesenchymal transition generates cells with properties of stem cells. Cell 2008, 133:704-715

37. Bonventre JV, Yang L: Cellular pathophysiology of ischemic acute kidney injury. J Clin Invest 2011, 121:4210-4221

38. Dekel B, Biton S, Yerushalmi GM, Altstock RT, Mittelman L, Faletto D, Smordinski NI, Tsarfaty I: In situ activation pattern of Met docking site after renal injury and hypertrophy. Nephrol Dial Transplant 2003, 18:1493-1504 